\title{
Microbiota of an unpasteurised cellar-stored goat cheese from northern Sweden
}

\author{
Klara Båth ${ }^{1,2}$, Karin Neil Persson ${ }^{1}$, Johan Schnürer ${ }^{1}$ and Su-lin L. Leong ${ }^{1 *}$ \\ ${ }^{1}$ Swedish University of Agricultural Sciences, Dept of Microbiology, Uppsala Biocenter, Box 7025, \\ SE-75007 Uppsala, Sweden \\ ${ }^{2}$ SIK - The Swedish Institute for Food and Biotechnology, Box 5401, SE-402 29 Göteborg, Sweden \\ *e-mail: Su-lin.Leong@slu.se
}

\begin{abstract}
This qualitative study reports on lactic acid bacteria (LAB), yeasts and moulds isolated from three artisanal Swedish cellar-stored goat cheeses aged for 1, 3 and 5 months. Starter culture LAB dominated in the younger cheeses, and Leuconostoc pseudomesenteroides, common in raw goats' milk, had persisted from the unpasteurised milk into all the cheeses. Non-starter LAB dominated in the 5 month cheese, in particular, Lactobacillus sakei, a meat-associated LAB not previously isolated from cheese. Debaryomyces hansenii, and Penicillium and Mucor species were dominant among the yeasts and moulds, respectively. The cheese rind was not formed primarily from Penicillium species as in traditional cheeses such as Camembert - rather, mycelium from Mucor mucedo contributed to rind formation. Mould species known to produce sterigmatocystin, aflatoxins or ochratoxin A in cheese were not isolated in this study; growth of mycotoxigenic Aspergilli may have been inhibited by the cool conditions in the earth-cellar $\left(4-6^{\circ} \mathrm{C}\right)$.
\end{abstract}

Key words: maturation, lactic acid bacteria, yeasts, moulds

\section{Introduction}

The sparse pasture lands in northern Sweden have long favoured raising goats (browsers) over cows. Full-fat unpasteurised goats' milk is used in artisanal production of a semi-hard cheese, which is ripened in cool, underground cellars $\left(4-6^{\circ} \mathrm{C}\right)$. Acquisition of an often poorly-defined 'wild' mycobiota from caves or cellars is a key stage in the maturation of many artisan cheeses in southern Europe, e.g. Spanish blue-veined Cabrales (Flórez et al. 2006), and Turkish blue-veined Kuflu (Hayaloglu and Kirbag 2007). This Swedish cellar-stored goat cheese is unique in that the final product is not a blue cheese; instead, the growth of wild moulds contributes to both organoleptic properties and formation of a thick, often colourful rind (yellow, brown, pink, grey, white). The action of both starter and non-starter lactic acid bacteria (LAB), as well as yeasts during ripening also contributes to desirable sensory properties. The number of small-scale, artisan cheese-producers has doubled in Sweden during 2005-2011 (Rosengren 2012), yet little is known about the microbiota of unpasteurised artisan cheeses produced in Nordic countries, which may differ somewhat from other cheeses based on the initial microbiota in the raw milk, and the cooler maturation conditions. This study presents a qualitative report of the key microbiota - LAB, yeasts and moulds - associated with three goat cheeses ripened for 1, 3 and 5 months in an earth-cellar, with a main focus on assessing if moulds known to cause mycotoxin contamination of cheeses are among the wild mycobiota. 


\section{AGRICULTURAL AND FOOD SCIENCE}

K. Båth et al. (2012) 21: 197-203

\section{Materials and methods}

\section{Goat cheese production and storage}

Cheese samples were collected from Gärdnäs gård, a small farm in Jämtland, northern Sweden, near the city of Strömsund (58.5 latitude and 13.1 longitude). Cheesemaking followed fairly standard procedures: unpasteurised goats' milk not older than $24 \mathrm{~h}$ was warmed to $30^{\circ} \mathrm{C}$, after which rennet was added, as well as a mixed LAB starter culture containing Lactococcus lactis subsp. cremoris, Lactococcus lactis subsp. lactis, Leuconostoc mesenteroides subsp. cremoris and Lactococcus lactis subsp. diacetylactis (CHR Hansen, Hörsholm, Denmark). After separation from the whey, curds were broken, pressed, formed and laid to rest for $24 \mathrm{~h}$. Salt was rubbed onto the surface, and the cheeses laid to mature and ripen for 2-5 months in the earth cellar, on wooden shelves with a hessian (sackcloth) covering in front. The cellar was a former potato-cellar located below ground and accessed via an entrance in the garden. It is made of stone and earth, with a gravel floor. Conditions are fairly constant during the year, namely, $+4-6{ }^{\circ} \mathrm{C}$ and relative humidity $\sim 98 \%$, which encourage the growth of wild mould cultures on the surface of the cheese, yielding a characteristic taste and appearance.

\section{Sampling and microbiological analysis}

Samples were collected in July, 2008 and comprised raw goats' milk, and three cheeses which had been stored in the cellar for 1, 3 and 5 months, respectively. Samples were transported to the laboratory in a chilled box $\left(\sim+4{ }^{\circ} \mathrm{C}\right)$ and stored at either $-20^{\circ} \mathrm{C}$ (milk) or $+4{ }^{\circ} \mathrm{C}$ (cheeses) before microbial analysis.

\section{Lactic acid bacteria}

The cheese rind and interior were analysed separately. Approx. $10 \mathrm{~g}$ of sample of the cheese rind or interior was mixed for $2 \mathrm{~min}$ (Seward Stomacher 400 ) with sterile peptone solution $(0.02 \% \mathrm{w} / \mathrm{v}$ ) and dilution plated in duplicate on de Man Rogosa Sharpe agar (Oxoid), which was incubated in anaerobic conditions (GasPak system, Bectin Dickenson) at $30^{\circ} \mathrm{C}$ for $48 \mathrm{~h}$. To confirm the identity of these isolates of presumptive LAB and estimate the proportion of species present, 20 randomly-chosen colonies from each sample were further characterised by Repetitive-DNA-element-PCR fingerprinting using the microsatellite primer GTG (5'-GTGGTGGTGGTGGTG-3') (Olstorpe et al. 2008), after which representative strains from each profile were identified by colony-PCR and sequencing.

\section{Yeasts and moulds}

Yeasts were isolated by spread plating homogenised cheese rind / interior samples (described above) on MEA-C plates (Malt extract agar, Oxoid, with chloramphenicol $0.1 \% \mathrm{w} / \mathrm{v}$ ) which were incubated at $30{ }^{\circ} \mathrm{C}$ for $5 \mathrm{~d}$. Representative colonies from each sample were grown in pure culture and identified by sequencing (Olstorpe et al. 2008).

Moulds were not assessed by spread plating, as the high counts of heavily-sporulating species could mask the presence of common, but poorly-sporulating members. Instead, various sections of the cheese rind with different appearance or colour were sampled by drawing a sterile inoculation loop over the surface, and streaking this onto dichloran rose bengal chloramphenicol agar (Oxoid), dichloran $18 \%$ glucose agar base (Oxoid), and MEA plates, which were then incubated at $25^{\circ} \mathrm{C}$ for $7 \mathrm{~d}$. Representative mould colonies were subcultured on MEA plates for presumptive identification by microscopy, and also inoculated into glucose-yeast broth $\left(0.1 \% \mathrm{NH}_{4}\left(\mathrm{H}_{2} \mathrm{PO}_{4}\right), 0.01 \% \mathrm{KCl}, 0.02 \% \mathrm{MgSO}_{4} .7 \mathrm{H}_{2} \mathrm{O}, 1 \%\right.$ glucose, $0.5 \%$ yeast extract, 


\section{AGRICULTURAL AND FOOD SCIENCE}

K. Båth et al. (2012) 21: 197-203

$0.01 \%$ trace metal solution $\left[0.5 \mathrm{~g} \mathrm{CuSO}_{4}+1 \mathrm{~g} \mathrm{ZnSO}_{4}\right.$ in $100 \mathrm{ml} \mathrm{H}_{2} \mathrm{O}$ ]) for subsequent DNA extraction by the method of Cenis (1992). Non-Penicillium species were sequenced using primers ITS1F / ITS4 (White et al. 1990, Gardens and Bruns 1993), and Penicillium species, with primers bt2a / bt2b (Glass and Donaldson 1995). Isolates were identified by searching sequence databases in Genbank and Centraalbureau voor Schimmelcultures (CBS), with confirmation by microscopy. Penicillium subgen. Penicillium isolates were further cultivated at $25^{\circ} \mathrm{C}$ for $7 \mathrm{~d}$ on MEA, creatine sucrose agar, yeast extract sucrose agar, and Czapek yeast extract agar (also at $30^{\circ} \mathrm{C}$ ) for examination of colony size and appearance (Samson and Frisvad 2004). These data and the DNA sequences were combined for polyphasic identification using the CBS database (http://www.cbs.knaw.nl/penicillium/BioloMICSID.aspx).

\section{Results}

LAB naturally present in the unpasteurised goats' milk at $9 \times 10^{4} \mathrm{cfu} \mathrm{g}^{-1}$ comprised primarily L. lactis and Leuconostoc pseudomesenteroides. Addition of starter culture increased counts to $1 \times 10^{5} \mathrm{cfu}^{-1}$; thus, $90 \%$ of initial LAB can be said to originate from the goats' milk. LAB counts on the rind were lower than inside the cheeses (Fig. 1). Starter culture species, L. lactis and L. mesenteroides, dominated in the 1 and 3 month cheeses, but were absent from the 5 month cheese (Fig. 1). One species, L. pseudomesenteriodes, was present in raw milk and on the rind of all three cheeses. In the oldest cheese, non-starter LAB were dominant, viz. Enterococcus faecalis, E. faecium, Lactobacillus sakei and Staphylococcus epidermis.

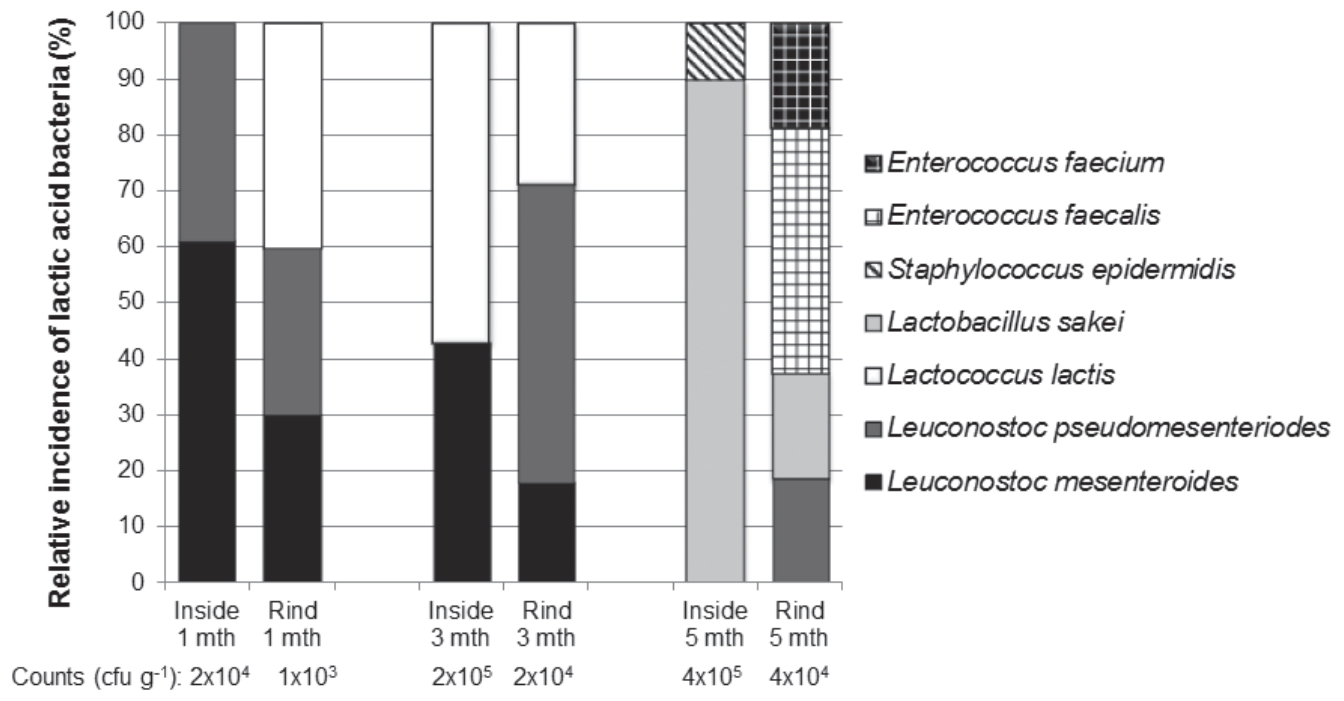

Fig. 1. Relative incidence of lactic acid bacteria inside and on the rind of three goat cheeses cellar-stored for 1,3 and 5 months. Starter culture species are shown in solid white or black. 


\section{AGRICULTURAL AND FOOD SCIENCE}

K. Båth et al. (2012) 21: 197-203

Debaromyces hansenii was the most common yeast isolated both from the rind (Table 1) and inside the three cheeses; Yarrowia lipolytica was also present on both rind and inside the 3 month cheese. Additional yeasts isolated only from inside the cheeses were Debaromyces nepalensis (cheese 1 month) and Cryptococcus statzelliae (cheese 3 months). Moulds isolated from the cheese rind comprised primarily Penicillium and Mucor spp. and the 5 month cheese yielded the greatest diversity of species (Table 1). A green mould isolated from air pockets in this cheese was identified as Penicillium roqueforti.

Table 1. Yeasts and moulds isolated from the rinds of three goat cheeses cellar-stored for 1, 3 and 5 months.

\begin{tabular}{lll}
\hline Cheese: 1 month & Cheese: 3 months & Cheese: 5 months \\
\hline Debaromyces hansenii & D. hansenii & D. hansenii \\
& Yarrowia lipolytica & Rhodotorula mucilaginosa \\
Penicillium caseifulvum & Penicillium aurantiogriseum & Doratomyces sp. \\
Penicillium cyclopium & P. caseifulvum & Geomyces pannorum \\
Penicillium palitans & P. cyclopium & Penicillium camemberti \\
Mucor mucedo & Penicillium griseofulvum & P. caseifulvum \\
Mucor fragilis & P. palitans & P. cyclopium \\
& Penicillium solitum & P. palitans \\
& Mucor racemosus & Penicillium roqueforti \\
& & P. solitum \\
& M. mucedo \\
\hline
\end{tabular}

\section{Discussion}

The LAB species in the cheeses followed a fairly typical pattern, with fewer counts on the dry rind than inside the cheeses, and a dominance of non-starter LAB in the oldest cheese, as these were likely selected for by the cellar-environment. Most of these species are commonly isolated from goat cheese (Flórez et al. 2006), and are likely to having arisen from minor members of the original biota or been acquired from the environment. It appeared that $L$. pseudomesenteriodes was able to persist from the original milk microbiota, as it was isolated from the rind of all three cheeses. One novel LAB which was dominant in the 5 month cheese was $L$. sakei, which has not previously been reported from dairy products, although it is well-adapted to protein-rich, acidic environments, being found on fresh meat and active in fermented meat products (Champomier-Vergés et al. 2001). Some strains grow at $2-4^{\circ} \mathrm{C}$, and such psychrophilic traits would be advantageous during cool cellar-storage.

The isolation of $D$. hansenii in all three cheeses is not surprising, given that it is arguably the dominant yeast associated with the majority of cheese types (Beresford et al. 2001). Most yeast species in Table 1 have previously been isolated from goats' milk and/or goat or ewe cheese (Tornadijo et al. 1998, PereiraDias et al. 2000, Spanamberg et al. 2009), where Y. lipolytica is thought to play an important role in the production of volatile fatty acids. Two novel species were isolated from the inside of cheeses: the arctic yeast, $C$. statzelliae, has not previously been isolated from cheese, and may have been acquired environmentally; likewise, D. nepalensis, which is soil-borne, and a halotolerant spoilage agent (Kumar et al. 2008). 


\section{AGRICULTURAL AND FOOD SCIENCE}

K. Båth et al. (2012) 21: 197-203

The frequent isolation of terverticillate Penicillium species (subgenus Penicillium) on these goat cheeses is in keeping with the close association of this group with cheeses in general, both as spoilage agents and as the dominant genus that artisan cheeses acquire from ripening caves or pits (Beresford et al. 2001, Hayaloglu and Kirbag 2007, Flórez et al. 2007, de Santi et al. 2010). Penicillium caseifulvum, P. palitans and $P$. solitum, are often associated with cheese production and/or spoilage (Samson and Frisvad 2004, Stark 2007). Additional species such as $P$. aurantiogriseum, $P$. cyclopium and $P$. griseofulvum are possibly opportunists species acquired from cereal or plant material outside the cellar or from soil. Other cheeses stored in the same cellar environment supported similar Penicillium species to the three cheeses analysed in this study (data not shown). In the 5 month cheese, the presence of the 'traditional' cheesemaking species, $P$. camemberti and $P$. roqueforti, may have resulted from cross-contamination in the dairy, which utilises starter cultures of those species in other cheese types. Of the species listed in Table 1, P. caseifulvum, $P$. griseofulvum and $P$. palitans were also isolated from the earth walls and floor of the cellar (data not shown), together with Penicillium freii; whether these represent a flow of mould propagules from the cellar environment to the cheese or vice versa is not clear. However, the increased number of mould species in the 5 month cheese, including the presence of soil-borne Geomyces and Doratomyces could suggest acquisition from the cellar-environment, shelving etc.

The Mucor species are thought to play a key role in rind formation - M. mucedo, in particular, is well adapted to cool cellar conditions as it prefers temperatures below $20^{\circ} \mathrm{C}$ (Schipper 1975). Many strains have sporangiophores $>5 \mathrm{~cm}$ in length, and these together with aerial mycelium are likely to contribute to the white-grey 'carpet' some $2 \mathrm{~cm}$ thick which forms on the cheese (Fig. 2). This was flattened regularly by the cheesemaker, yielding a thick rind of compacted fungal mycelium. Mucor mucedo was also previously isolated from Turkish Kuflu cheese matured in caves (Hayaloglu and Kirbag 2007); and Zhang and Zhao (2010) proposed the use of Mucor spp. as alternative surface-ripening cultures to the traditional Penicillium spp. inoculated onto, say, Camembert or Brie. Indeed, Mucor is surface-inoculated in the production of Norwegian gammalost (Beresford et al. 2001). The key role in rind formation played by the 'wild' environmentally-acquired Mucor spp. in our artisan cheese further demonstrates the potential of this genus for the surface-ripening of novel cheese types.

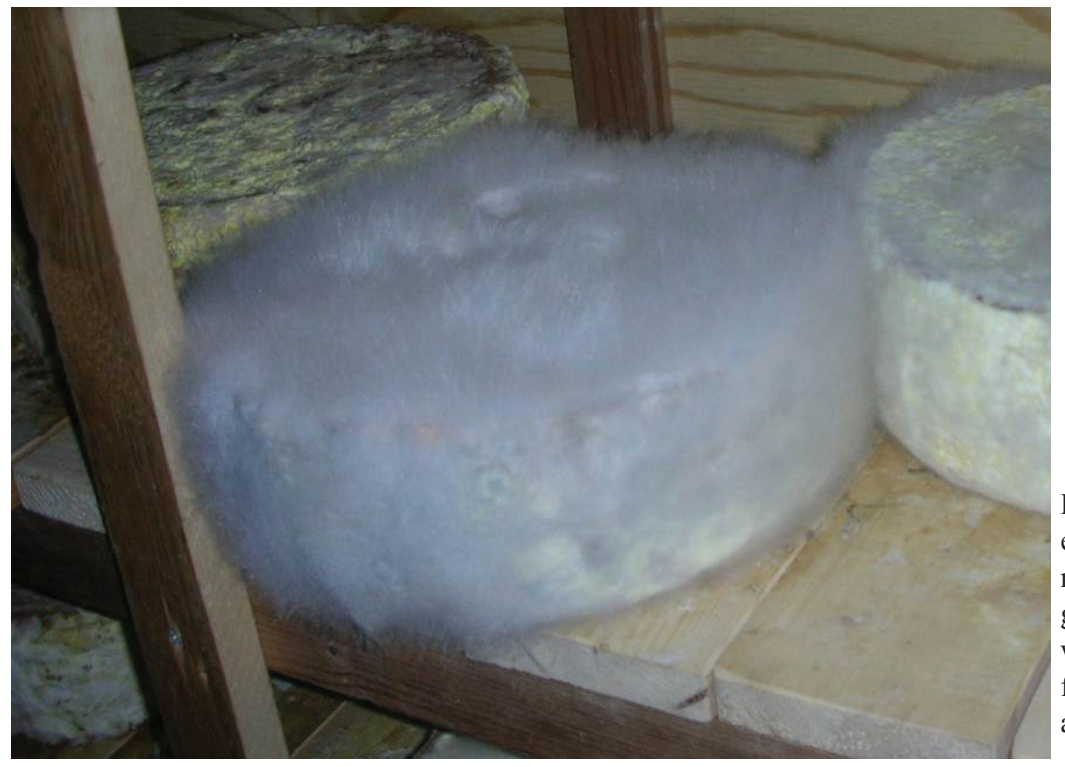

Fig. 2. Cheese stored in the earth-cellar, showing aerial mycelium and long sporangiophores of Mucor species which contribute to rind formation when brushed flat against the cheese surface. 


\section{AGRICULTURAL AND FOOD SCIENCE}

K. Båth et al. (2012) 21: 197-203

In considering the potential risk for mycotoxin-production in cheese by the wild mycobiota, it should be noted that the majority of species belonging to Penicillium subgenus Penicillium produce a wide range of secondary metabolites, many of which are classified as mycotoxins: the species isolated in this study could potentially produce, for example, cyclopiazonic acid, mycophenolic acid, patulin, penicillic acid, PR toxin, verrucosidin (Samson and Frisvad 2004). However, it is not known whether these toxins are actually produced during mould growth on cheeses e.g. xanthomegnin, viomellein, vioxanthin are known to be produced by P. cyclopium, but in cereals. Mycotoxins previously detected in cheeses include sterigmatocystin (most common mycotoxin in cheese, produced by Aspergillus versicolor), aflatoxins (Aspergillus flavus / Aspergillus parasiticus), ochratoxin A (Penicillium nordicum), patulin (P. griseofulvum), cyclopiazonic acid (P. camemberti, P. palitans, P. griseofulvum), roquefortine and mycophenolic acid ( $P$. roqueforti) (Frisvad et al. 2007, Stark 2007, Pitt and Hocking 2009). Of these toxins, only aflatoxins, ochratoxin and patulin are regulated in foods in the EU (Lerda 2011), and none are present in cheeses at levels considered to be a public health risk (Pitt and Hocking, 2009). Among the wild mycobiota in our cellar-stored cheeses, aflatoxin and ochratoxin A producers were absent; one potential producer of patulin, $P$. griseofulvum, was isolated from the 3 month cheese (Table 1), but this was not a common species (data not shown). Thus, species comprising the 'wild' moulds on these cellar-stored cheeses are unlikely to pose an alarming risk for mycotoxin production of public health significance. Growth of high-risk mycotoxin producers previously isolated from goat cheese, such as A. flavus (Barrios et al. 1997), was probably suppressed by the low temperatures in the underground earth-cellar $\left(4-6^{\circ} \mathrm{C}\right)$, which are even lower than in caves used for mould-ripening in Spain or Turkey $\left(6-12{ }^{\circ} \mathrm{C}\right.$; Hayaloglu and Kirbag 2007, Flórez et al. 2006). The low temperatures may have also somewhat limited the overall diversity of both moulds and yeasts.

\section{Conclusion}

Non-starter LAB dominated in the oldest (5 month) cellar-stored goat cheese, and L. sakei may represent a novel species contributing to the organoleptic properties of this Swedish artisan cheese. Two novelties in these cheeses were: the dominance of $L$. sakei in the oldest cheese; and rind formation from mycelium of Mucor spp. Risk for mycotoxin contamination of public health significance in these cheeses appears minimal, as moulds producing aflatoxins, ochratoxin or patulin were not dominant members of the wild mycobiota.

\section{Acknowledgements}

We thank Helen Sjölund Isaksson, cheesemaker and owner of Gärdnas Gård.

\section{References}

Barrios, M.J., Medina, L.M., Cordoba, M.G. \& Jordano, R. 1997. Aflatoxin-producing strains of Aspergillus flavus isolated from cheese. Journal of Food Protection 60: 192-194.

Beresford, T.P., Fitzsimons, N.A., Brennan, N.L. \& Cogan, T.M. 2001. Recent advances in cheese microbiology. International Dairy Journal 11: 259-274.

Cenis, J.L. 1992. Rapid extraction of fungal DNA for PCR amplification. Nucleic Acids Research 20:2380.

Champomier-Vergés, M.C., Chaillou, S., Cornet, M. \& Zagorec, M. 2001. Lactobacillus sakei: recent development and future perspectives. Research in Microbiology 152: 839-848. 


\section{AGRICULTURAL AND FOOD SCIENCE}

K. Båth et al. (2012) 21: 197-203

de Santi, M., Sisti, M., Barbieri, E., Piccoli, G., Brandi, G. \& Stocchi, V. 2010. A combined morphologic and molecular approach for characterizing fungal microflora from a traditional Italian cheese (Fossa cheese). International Dairy Journal 20: 465-471.

Flórez, A.B., López-Díaz, T.M., Álvarez-Martín, P. \& Mayo, B. 2006. Microbial characterisation of the traditional Spanish blue-veined Cabrales cheese: identification of dominant lactic acid bacteria. European Food Research and Technology 223: 503-508.

Flórez, A.B., Álvarez-Martín, P., López-Díaz, T.M. \& Mayo, B. 2007. Morphotypic and molecular identification of filamentous fungi from Spanish blue-veined Cabrales cheese, and typing of Penicillium roqueforti and Geotrichum candidum isolates. International Dairy Journal 17: 350-357.

Frisvad, J.C., Thrane, U. \& Samson, R.A. 2007. Mycotoxin producers. In: Dijksterhuis, J. \& Samson, R.A. (eds). Food mycology. A multifaceted approach to fungi and food. Boca Raton: CRC Press. p. 135-159.

Gardes, M. \& Bruns, T.D.1993. ITS primers with enhanced specificity for basidiomycetes - application to the identification of mycorrhizae and rusts. Molecular Ecology 2: 113-118.

Glass, N.L. \& Donaldson, G.C. 1995. Development of primer sets designed for use with the PCR to amplify conserved genes from filamentous ascomycetes. Applied and Environmental Microbiology 61: 1323-1330.

Hayaloglu, A.A. \& Kirbag, S. 2007. Microbial quality and presence of moulds in Kuflu cheese. International Journal of Food Microbiology 115: 376-380.

Kumar, S., Lal, P. \& Gummadi, S.N. 2008. Growth of halotolerant food spoiling yeast Debaromyces nepalensis under the influence of pH and salt. Current Microbiology 57: 598-602.

Lerda, D. 2011. Mycotoxins Fact Sheet $4^{\text {th }}$ edition. JRC Technical Notes. http://irmm.jrc.ec.europa.eu/EURLs/eurl_mycotoxins/Documents/Factsheet\%20Mycotoxins.pdf. Cited 15 May, 2012.

Olstorpe, M., Lyberg, K., Lindberg, J.E., Schnürer, J. \& Passoth, V. 2008. Population diversity of yeasts and lactic acid bacteria in pig feed fermented with whey, wet wheat distillers' grains, or water at different temperatures. Applied and Environmental Microbiology 74: 1696-1703.

Pereira-Dias, S., Potes, M.E., Marinho, A., Malfeito-Ferreira, M. \& Loureiro, V. 2000. Characterisation of yeast flora isolated from an artisanal Portuguese ewes' cheese. International Journal of Food Microbiology 60: 55-63.

Pitt, J.I. \& Hocking, A.D. 2009. Fungi and Food Spoilage. 3rd ed. New York: Springer. 519 p.

Rosengren, A. 2012. Microbiological food safety of cheese produced in Swedish small-scale dairies. Licentiate thesis. Uppsala: Swedish University of Agricultural Sciences.

Samson, R.A. \& Frisvad, J.C. 2004. Penicillium subgenus Penicillium: new taxonomic schemes, mycotoxins and other extrolites. Studies in Mycology 49: 1-260.

Schipper, M.A.A. 1975. On Mucor mucedo, Mucor flavus and related species. Studies in Mycology 10: 1-159.

Spanamberg, A., Ramos, J.P., Leoncini, O., Alves, S.H. \& Valente, P. 2009. High frequency of potentially pathogenic yeast species in goat's raw milk and creamed cheese in Southern Brazil. Acta Scientiae Veterinariae 37: 133-141.

Stark, J. 2007. Cheese and fermented sausages. In: Dijksterhuis, J. \& Samson, R.A. (eds). Food mycology. A multifaceted approach to fungi and food. Boca Raton: CRC Press. p. 319-331.

Tornadijo, M.E., Fresno, J.M., Sarmiento, R.M. \& Carballo, J. 1998. Study of the yeasts during the ripening process of Armada cheeses from raw goat's milk. Le Lait 78: 647-659.

White, T.J., Bruns, T., Lee, S. \& Taylor, J.W. 1990. Amplification and direct sequencing of fungal ribosomal RNA genes for phylogenetics. In: Innis, M.A., Gelfand, D.H., Sninsky, J.J. \& White, T.J. (eds). PCR protocols: a guide to methods and applications. San Diego: Academic Press, Inc. p. 315-322.

Zhang, N. \& Zhao, X.-H. 2010. Study of Mucor spp. in semi-hard cheese ripening. Journal of Food Science and Technology 47: 613-619. 